УДК 911.338.485:39 (571.1)

ПРОБЛЕМЫ ИСПОЛЬЗОВАНИЯ КУЛЬТОВЫХ ОБЪЕКТОВ КОРЕННЫХ НАРОДОВ В ИНДУСТРИИ ТУРИЗМА (ОПЫТ АЛТАЕ-САЯНСКОГО РЕГИОНА)

Елизавета В. Чайкина ${ }^{1, @ 1, ~ *, ~ К о н с т а н т и н ~ И . ~ О с и п о в, ~ @ 2, ~ * ~}$

${ }^{1}$ Кемеровский государственный университет, Россия, 650000, г. Кемерово, ул. Красная, 6

@1 litvinova912@mail.ru

@2constantine-osipov@yandex.ru

Поступила в редакциюю 30.11.2017. Принята к печати 21.12.2017.

Ключевые слова: сакральные места, культовые объекты, места силы, коренные народы, туризм, сакральный туризм, АлтаеСаянский регион.
Аннотация: Культовые объекты играют важную роль в жизнедеятельности коренных народов Севера, они аккумулируют сведения об истории, традиционной культуре и природопользовании местных сообществ. В настоящее время многие из них постепенно исчезают или находятся в неудовлетворительном состоянии. В последнее время сакральные места пользуются большой популярностью среди туристов, в связи с чем, они становятся объектами различных направлений туристической сферы. В статье поднимается актуальная проблема вовлечения сакральных мест коренных народов Севера в туристические маршруты. Кроме того, рассматривается имеющийся опыт регионов Южной Сибири по организации туризма в окрестностях культовых объектов.

В результате исследования автор работы приходит к выводу о том, что развитие туризма в местах силы коренных народов Севера имеет как положительные, так и отрицательные аспекты.

Для предотвращения негативных последствий использования культовых объектов в индустрии туризма приводятся практические рекомендации по его организации. В заключении статьи отмечается, что при правильной организации туризм является одним из эффективных инструментов поддержания и развития сакральных мест в Алтае-Саянском регионе.

Для цитирования: Чайкина Е. В., Осипов К. И. Проблемы использования культовых объектов коренных народов в индустрии туризма (опыт Алтае-Саянского региона) // Вестник Кемеровского государственного университета. Серия: Биологические, технические науки и науки о Земле. 2017. № 4. С. 56-59. DOI: 10.21603/2542-2448-2017-4-56-59.

Сакральные места представляют собой природные объекты (гора, озеро, роща, источник, участок степи, место слияния рек), часто обозначенные присутствием культовых объектов, таких как: мегалиты, менгиры, дольмены, каменные лабиринты, петроглифы, курганы и др. [1]. Они играют важную роль в жизненном укладе коренных народов, так как являются своеобразными мостами взаимосвязи людей с божественными силами, а также символами единения человека с природой. Сакральные места накапливают сведения об истории, традиционной культуре и природопользовании местных сообществ. В настоящее время многие культовые объекты постепенно исчезают или находятся в неудовлетворительном состоянии.

На сегодняшний день сакральные места пользуются большой популярностью среди туристов. В связи с этим они становятся объектами различных видов туризма: культурно-исторического, экологического, этнографического, сакрального, религиозного и паломнического. Поэтому актуальным является вопрос изучения прямого и косвенного влияния индустрии туризма на состояние культовых объектов. В контексте данной проблематики автор данной работы предполагает, что туризм может стать эффективным инструментом восстановления сакральных мест.

Сакральные объекты коренных малочисленных народов Алтае-Саянского региона представлены археологическими памятниками, поминально-ритуальными сооружениями, памятниками природы, ландшафтными комплексами и др. Большинство из них являются привлекательными с точки зрения развития туризма и используются в данной области.

В Алтайском крае проводятся экскурсионные маршруты к следующим сакральным объектам: Царский курган, гора Бабырган, Большая Тавдинская пещера.

Царский курган - это памятник археологии эпохи скифов, время его образования - около V века до нашей эры. Имеется несколько легенд о назначении данного места, наиболее знаменитая о том, что данный комплекс был научной обсерваторией для жрецов. В настоящее время Царскому кургану присвоен статус музейного памятника под открытым небом. Туристская инфраструктура отсутствует [2].

\footnotetext{
* Исследование выполнено при финансовой поддержске РФФИ в рамках научных проектов № 17-01-18076 «Этнологическая экспертиза: этносоциальные процессы и новые идентичности «малочисленных» этнических групп Республики Тыва в современном контексте»; № 17-11-42601 «Шорцы Кемеровской области: сакральное пространство культуры малочисленного этноса в контексте геоинформационного исследования факторов земельных конфликтов»; № 16-46-420035 «Коренные малочисленные этносы Кемеровской области под воздействием угольных компаний: социальные и экологические факторы развития конфликтов в районах угледобычи в контексте мирового опыта междисциплинарных исследований и практик управления».
} 
Гору Бабырган называют древним святилищем алтайского народа. Это связано с тем, что здесь в древние времена проводились камлания, поскольку она являлась родовой тотемной для нескольких местных алтайских родов: сеоков, тодош, очы, чапты и чагандык. В 1998 году горе Бабырган был присвоен статус памятника природы Алтайского края. Учёные и представители местного населения заинтересованы в восстановлении данного культового объекта, посредством развития экологического туризма, а также создания условий для детского и семейного отдыха. Однако этот процесс идёт крайне медленно, поскольку требует определённых целенаправленных мероприятий и денежных инвестиций. В связи с этим, пока здесь из туристической инфраструктуры только одноименный пруд у подножия горы, где организована платная рыбалка, где проводятся соревнования по ловле рыбы спиннингом с лодок, также присутствует баня [3].

Большая Тавдинская пещера - это памятник природы Алтайского края. В результате археологических раскопок в ней были обнаружены следы времени скифов и раннего энеолита. Есть мнение о том, что Большая Тавдинская пещера - культовое место. В наши дни пещера является популярным экскурсионным объектом, где в летнее время проводится множество экскурсий. Для данной разновидности отдыха в пещере созданы необходимые условия: проведено электрическое освещение, в труднодоступных местах установлены лестницы, туристам выдаются каски и фонарики [4].

В Республике Алтай большой популярностью у туристов пользуются такие культовые объекты как плоскогорье Укок, массив горы Белухи, гора Уч-Энмек, с. Чемал (о. Патмос, урочище Чечкыш).

Плато Укок - уникальное по климатическим, географическим, природным особенностям плоскогорье Республики Алтай. Объект Всемирного природного наследия ЮНЕСКО. Для местного населения Республики Алтай плато Укок является хранилищем истории предков, священным местом. В данный момент на плоскогорье Укок организуются различные активные туры: автомобильные, конные, пешие, джипп-туры. Следует обратить внимание на то, что автомобильные и джипп-туры не отличаются экологическим характером и наносят вред природе данного района. Также организованная для туристов рыбалка, может отразиться на уникальном биоразнообразии территории [5].

Гора Белуха - высшая точка Сибири. Коренные жители Республики Алтай почитают Белуху и считают её священной горой. Коренное население считает, что данная гора принимает информацию из Космоса, преобразует её и распространяет по всей Земле. Некоторые люди могут распознавать её информационные потоки. Доказано, что гора оказывает гармонизирующее влияние на человека, увеличивая его чувствительность и любовь к природе. Туристическими фирмами предлагаются активные туры с посещением данного культового объекта: восхождения, зимние туры (снегоходно-лыжные), комбинированные (джипы и кони, конно-водные, пеше-водные), конные, пешеходные [6].

Гора Уч-Энмек является сакральной для местного населения Республики Алтай. На сегодняшний день гора и её окрестности входят в состав особо-охраняемой территории - парка «Уч-Энмек». Цель его образования - сохране- ние памятников природного и историко-культурного наследия коренного населения Горного Алтая. С помощью парка сохраняется традиционная культура населения, представляющая уникальный природно-этнокультурный комплекс, развивается духовно-экологический, научный и оздоровительный туризм, основанный на этно-экологических традициях алтайцев и старообрядцев [7].

Село Чемал - крупный туристский центр Республики Алтай. Остров Патмос и возведённая на нём Церковь иконы Божией Матери «Всех скорбящих Радость» представляет собой объект паломнического и религиозного туризма. Урочище Чечкыш - сакральное место для коренных жителей. На данный момент в пределах данного села созданы необходимые условия для развития индустрии туризма [8].

В Республике Хакасии объектами сакрального туризма становятся: горная гряда Сундуки, Большой Салбыкский курган, каменное изваяние Ах-Хуртуях-Тас.

Горная гряда Сундуки - одно из уникальных мест Хакасии, Где, по мнению некоторых учёных, осуществлялись наблюдения за звездами. Данное место рассматривается в качестве древней обсерватории. Окрестности горной гряды Сундуки заряжены определённой энергетикой, в результате чего чувствительные люди могут увидеть здесь параллельные миры, а также прошлое и будущее. Поэтому данная территория востребована среди туристов для восстановления как физических, так и духовных сил.

Большой Салбыкский курган сооружён в III веке до нашей эры над могилой знаменитой семьи тагарцев. В его окрестностях на протяжении многих веков наблюдаются аномальные явления. Сила данного места привлекает туристов, которые приезжают для оздоровления. Также на кургане шаманы проводят обряд очищения, обновляя энергию человека.

Каменное изваяние Хуртуях-Тас является сакральным для хакасского населения и обладает целебной силой. По преданиям данный камень помогает справиться женщинам с бесплодием. В настоящее время в районе каменного изваяния Хуртуях-тас создан одноимённый музей под открытым небом, который оказывает туристам ряд услуг: проведение традиционных экскурсий, дегустация национальных блюд, выступления хакасских фольклорных коллективов, организация шаманских обрядов, продажа национальных сувениров, организация и проведение национальных свадеб [9].

Республика Тыва притягивает туристов к местам силы, таким как горы: Монгун-Тайга, Мандала-Таг, ШивээлигДаг, Бай-Тайга, Ак-Хайыракан.

Монгун-Тайга - самая высокая точка Тывы. Данная гора и её окрестности относятся к заповедному кластеру памятника Всемирного наследия ЮНЕСКО («Бассейн Убсу-Нура»). Местные жители считают, что МонгунТайга священна, и простым людям заходить сюда не стоит - путь открыт только избранным. Восхождение на гору даёт человеку энергетическое очищение.

Мандала-Таг символизирует буддизм, сферу обитания божеств, чистые земли будд. У её подножия возник первый монастырь, ставший одним из центров зарождения буддизма в Тыве. В настоящее время данное место привлекает большое количество паломников. 
Шивээлиг-Даг, возможно, была сакральным местом на протяжении нескольких веков. Здесь были обнаружены многочисленные курганы и наскальные рисунки, относящиеся к разным периодам времени.

Бай-Тайга сакральна для тувинского населения. Местные жители считают, что на её вершине проживает Дух - Хозяин всей Тывы, который никого сюда не пускает. Добраться до вершины горы Бай-Тайги ещё никому не удалось. У её подножия расположено Зелёное озеро Ногаан Холь, воды которого, по мнению населения, целебны. Озеро является местом шаманской силы. Ежегодно в начале июня здесь проходит большой тувинский праздник - Освящение Оваа (обитель Духа) горы Бай-Тайга. Туристы посещают данное место для укрепления своей духовной и физической связей с природой.

Гора Ак-Хайыракан священна, род «Кыргыс» считает её своей прародиной. На южном склоне расположен аржаан Ак-Хайыракан, вода которого лечебна и помогает при желудочных недомоганиях, заболеваниях опорно-двигательного аппарата, нервных расстройствах. К сожалению, источник слабеет и уже с трудом наполняет водой бессчетные сосуды приезжающих паломников. У аржаана постоянно проводятся шаманские и буддистские обряды [10].

Необходимо отметь, что использование культовых объектов коренных народов Севера в индустрии туризма имеет как положительные, так и отрицательные аспекты. К позитивным сторонам организации туристических маршрутов в местах силы можно отнести следующие: учёт сакральных объектов, их музеефикация, сохранение и развитие культовых объектов, развитие инфраструктуры в их окрестностях, контроль потока туристов и при необходимости его ограничение и т. д. К отрицательным сторонам относятся: высокая антропогенная нагрузка, которая приводит к трансформации внешнего облика и биотического разнообразия культовых объектов, загряз- нение и осквернение сакральных мест, утрата сакрального значения объектов и т. д.

Для предотвращения негативных последствий туристического бизнеса в местах силы необходимо соблюдать ряд условий: в регионах должен осуществляться учёт и изучение квалифицированными специалистами сакральных мест, их истории и значимости для местного населения с целью определения возможности их использования в туристических маршрутах. Те объекты, которые обладают наибольшим сакральным смыслом, имеют важное этнокультурное значение для сообществ коренных народов, следует оградить от посещения туристами. В создании туристических маршрутов и брендов, связанных с культовыми объектами, участие должны принимать как работники туристических фирм, так и представители коренного населения. В первую очередь, акцент должен быть на интересе местных жителей, что позволит исключить возможные конфликты с туристами, а также будет способствовать возрождению традиционных знаний коренных народов о сакральном смысле культовых объектов и передаче этих знаний молодому поколению. Для успешного позиционирования сакральных мест на рынке туризма важна организация определённых услуг: сбор и вывоз мусора, установка информационных стендов, облагораживание территорий вблизи культовых объектов. Данный комплекс позволит создавать новые туристические продукты, смыслом которых будет не только коммерческая выгода, но и сохранение, развитие традиционной культуры коренного населения, а также его компонентов - культовых и сакральных мест.

В заключение, необходимо отметить, что при правильной организации туризм может быть рассмотрен как один из способов восстановления и поддержания культовых мест коренных народов Севера.

\section{Литература}

1. Мельникова Е. Е. Культовые объекты в Алтайском крае и Республике Алтай и их использование для развития сакрального туризма // География, история и геоэкология на службе науки и инновации: материалы Международной научно-практической конференции, 22-23 апр. 2011. Красноярск, 2011. С. 134-135.

2. Царский курган. Режим доступа: http://www.turistka.ru/altai/info.php?ob=561 (дата обращения: 18.11.2017).

3. Гора Бабырган. Режим доступа: http://www.turistka.ru/altai/info.php?ob=752 (дата обращения: 12.11.2017).

4. Тавдинские пещеры. Режим доступа: http://www.turistka.ru/altai/info.php?ob=388 (дата обращения: 25.09.2017).

5. Плато Укок. Режим доступа: http://www.turistka.ru/altai/info.php?ob=962 (дата обращения: 25.11.2017).

6. Гора Белуха. Режим доступа: http://www.turistka.ru/altai/info.php?ob=787 (дата обращения: 01.10.2017).

7.Природный парк Уч-Энмек. Режим доступа: http://www.turistka.ru/altai/info.php?ob=1358 (дата обращения: 08.11.2017).

8. Село Чемал. Режим доступа: http://www.turistka.ru/altai/info.php?ob=6 (дата обращения: 11.08.2017 г.).

9. Моруденко Ю. И. Сакральные памятники Хакасии как объекты этнографического туризма // Стратегия развития индустрии туризма и гостеприимства: материалы четвертой Международной интернет-конференции, 24 янв. - 21 апр. 2011 г. Орёл, 2011. С. 354-357.

10. Республика Тыва. Режим доступа: http://vladimir.nosov.org/category/tyva (дата обращения: 25.08.2017). 


\title{
THE ISSUES OF THE USE OF INDIGENOUS SACRAL OBJECTS IN TOURIST INDUSTRY (EXPERIENCE OF THE ALTAI-SAYAN REGION)
}

Elizaveta V.Chaikina ${ }^{1,1, ~ *, ~ K o n s t a n t i n ~ I . ~ O s i p o v ~}{ }^{1, @ 2, ~ * ~}$

\author{
${ }^{1}$ Kemerovo State University, 6, Krasnaya St., Kemerovo, Russia, 650000 \\ @1litvinova912@mail.ru \\ @2constantine-osipov@yandex.ru
}

Received 30.11.2017. Accepted 21.12.2017.

Keywords: sacred places, places of worship, places of power, indigenous peoples, tourism, sacral tourism, the Altai-Sayan region.

\begin{abstract}
Religious objects play an important role in the vital activity of the indigenous peoples of the North, as they accumulate information about the history, traditional culture and the use of local communities. Currently, many of them are gradually fading away or in an unsatisfactory state. Sacred places are getting more and more popular with tourists, which turns them into touristic destinations. That is why the article raises the pressing challenge of including the sacred places of the Northern indigenous peoples into tourist routes.

The article examines the experience of the regions of Southern Siberia in organizing tourism near religious sites.

As a result of the research, the author comes to the conclusion that the development of tourism in places of power of the indigenous peoples of the North has both positive and negative aspects. The paper gives a number of practical recommendations that would prevent negative consequences of the use of religious objects in tourism. In the conclusion of the article it is said that, with proper organization, tourism can be one of the most effective tools for maintaining and developing the sacred sites in the Altai-Sayan region.
\end{abstract}

For citation: Chaikina E. V., Osipov K. I. Problemy ispol'zovaniia kul'tovykh ob»ektov korennykh narodov v industrii turizma (opyt Altae-Saianskogo regiona) [The Issues of the Use of Indigenous Sacral Objects in Tourist Industry (Experience of the Altai-Sayan Region)]. Bulletin of Kemerovo State University. Series: Biological, Engineering and Earth Sciences, no. 4 (2017): 56-59. DOI: 10.21603/2542-2448-2017-4-56-59.

\section{References}

1. Melnikova E. E. Kul'tovye ob»ekty v Altaiskom krae i Respublike Altai i ikh ispol'zovanie dlia razvitiia sakral'nogo turizma [Religious objects in the Altai Territory and the Altai Republic and their use for the development of sacral tourism]. Geografiia, istoriia i geoekologiia na sluzhbe nauki i innovatsii: materialy Mezhdunarodnoi nauchno-prakticheskoi konferentsii, 22-23 aprelia 2011 [Geography, history and geoecology at the service of science and innovation: materials of the International Scientific and Practical Conference, April 22-23, 2011]. Krasnoiarsk, 2011, 134-135.

2. Tsarskii kurgan [The Imperial Mound]. Available at: http://www.turistka.ru/altai/info.php?ob=561 (accessed 18.11.2017).

3. Gora Babyrgan [Mountain Babyrgan]. Available at: http://www.turistka.ru/altai/info.php?ob=752 (accessed 12.11.2017).

4. Tavdinskie peshchery [Tavdinsky caves]. Available at: http://www.turistka.ru/altai/info.php?ob=388 (accessed 25.09.2017).

5. Plato Ukok [Ukok Plateau]. Available at: http://www.turistka.ru/altai/info.php?ob=962 (accessed 25.11.2017).

6. Gora Belukha [Mountain Belukha]. Available at: http://www.turistka.ru/altai/info.php?ob=787 (accessed 01.10.2017.).

7. Prirodnyi park Uch-Enmek [Nature Park Uch-Enmek]. Available at: http://www.turistka.ru/altai/info.php?ob=1358 (accessed 08.11.2017).

8. Selo Chemal [Cheml village]. Available at: http://www.turistka.ru/altai/info.php?ob=6 (accessed 11.08.2017).

9. Morudenko Iu. I. Sakral'nye pamiatniki Khakasii kak ob»ekty etnograficheskogo turizma [Sacred monuments of Khakassia as objects of ethnographic tourism]. Strategiia razvitiia industrii turizma i gostepriimstva: materialy chetvertoi Mezhdunarodnoi internet-konferentsii, 24 ianvaria - 21 aprelia 2011 [Strategy for the development of the tourism and hospitality industry: materials of the fourth International Internet Conference, January 24 - April 21, 2011]. Orel, 2011, 354-357.

10. Respublika Tyva [Tyva Republic]. Available at: http://vladimir.nosov.org/category/tyva (accessed 25.08.2017).

\footnotetext{
* The research was carried out with the financial support of the Russian State Scientific Foundation and the Administration of the Kemerovo Region within the framework of the scientific project No. 17-11-42601 «The Shors of the Kemerovo region: the sacred space of a small ethnos culture in the context of the geoinformation study of the factors of land conflicts»; № 16-46-420035 "Indigenous Peoples of Kemerovo Region Under the Pressure from Coal-Mining Companies: Societal and Environmental Roots of Conflicts Escalation in the Mining Territories in Context of World's Interdisciplinary Research \& Management Experience.
} 